\title{
Buying stock market winners on Warsaw Stock Exchange - quantitative backtests of a short term trend following strategy
}

\author{
Aleksander Fafuła \\ Wrocław University of Economics \\ ul. Komandorska 118/120 53-345 Wrocław \\ Email: aleksander@fafula.com
}

\author{
Krzysztof Drelczuk \\ Wrocław University of Economics \\ ul. Komandorska 118/120 53-345 Wrocław \\ Email: krzysztof.drelczuk@gmail.com
}

\begin{abstract}
This paper focuses on one of the most popular issues in the Polish finance - is the 'buying stock market winners' profitable on the Warsaw Stock Exchange? This study tested whether Ichimoku trend following strategy performed better than simple buy \& hold benchmark. For automated backtests WIG30 index components in the period 2012-12-28 to 2015-0506 were used. The empirical results suggest that buying recent "winners" is very ineffective. These preliminary findings may imply contrarian nature of the short-term Polish financial market.
\end{abstract}

\section{INTRODUCTION}

$\mathrm{T}$ RADERS take many investing approaches. One of these tactics is to buy well-performing companies with expectations the performance will continue. The decision can be made using either, among others: momentum, or trend following strategies. These strategies may appear similar, but in reality they use different assumptions.

Trend following is an investment or trading strategy that tries to take advantage of long, medium or short-term price movements that seem to play out in various markets. Traders who employ a trend following strategy do not aim to predict specific price levels; they simply jump on the trend (when they perceive that a trend has established with their own peculiar reasons or rules) and ride it. A market "trend" is a tendency of a financial market price to move in a particular direction over time. If there is a turn contrary to the trend, they exit and wait until the turn establishes itself as a trend in the opposite direction. In cases their rules signal an exit, the trader closes long positions and re-enters when the trend is re-established $[1,2]$.

Momentum strategies rely on the assumption that prices respond (at least in part) to the strength of their supply and demand inputs. Momentum takes many forms: the earnings reports for publicly traded companies, the relationship between buyers and sellers in the market, the typical rate of historical price rises and falls, etc. In a sense, momentum trading can be paradoxically concerned with the fundamentals of technical analysis [3].

There are many trend following strategies [4]. For instance "Cross Exponential Moving Average (EMA)" enters the market when candle closes above 5-period EMA and exits when candle closes below 20-period EMA. "Simple Moving Average (SMA) and Moving Average
Convergence Divergence (MACD)" on the other hand, enter the market when price crosses 20-period (this value can be adjusted) EMA and MACD oscillator is positive. Most strategies are based on fairly simple indicators operating on short-term historical prices. Due to that feature of trendfollowing strategies, authors have chosen Ichimoku method. This method sometimes is called trading system due to its complexity comparing to standard trend following techniques. Ichimoku is also a moving average-based trend identification system, but it contains more data points than standard candlestick charts and provides a clearer picture of potential price action. Authors have chosen this technique not because it is better than the others, not because it performs better or worse but because it takes into consideration much more aspects of price than other strategies. This feature of this technique is crucial for quantitative backtests performed in this paper.

This paper re-examines the profitability of a short-term trend following strategy, which aims to buy stocks that have performed well in the past. These backtests do not include short-sale trades. It is not the author's intention to prove or disprove efficiency of Ichimoku technique. The main question to be answered is: does buying recent winners from the WIG30 index pay off.

The question of profitability of the trend following strategy on the Warsaw Stock Exchange (WSE) is important because existing evidence provides mixed results. Numerous scientists documented abnormal profits of the momentum or trend following strategies. Rouwenhorst [5] finds it on twelve European markets, and [6] for some stock emerging markets. Hameed and Yuanto [7] positively identify six Asian markets. Schiereck, DeBondt and Weber [8] find momentum profitable for intermediate-term German market. In contrast to these findings there are numerous examples of contrarian markets. For example Jagadeesh [9] and Lehmann [10] find reversals in short-term horizons. DeBondt and Thaler [11, 12] report long-term price reversals. Chang, McLeavey and Rhee [13] document shortterm contrarian nature of Japan. Hameed and Ting [14] have similar findings about Malaysia. Finally Kang, Liu, and $\mathrm{Ni}$ [15] report the overreaction to firm-specific information as the single most important source of the short-term contrarian profit in China stock market. The state of short-term trend following on Polish WSE lacks similar conclusions. 


\section{METHOD}

For the purpose of the backtests an automated tradingagent was implemented. Basically the agent buys and sells stocks according to hard-coded Ichimoku rules. The testing framework is a part of the A-Trader system [16]. Presented work is an extension and follow-up of previous experiments conducted using A-Trader. Technically, the presented system is a multi-agent solution that supports the analysis of the time series of high frequency, such as trading instruments. The main features are its openness for integration, development of new system functionality and ensuring adequate communication between the various agents. The agents can act as data providers, indicators or final decision makers. The service orientated architecture and cloud computing solves the problem of computing power. This could be an issue for higher than daily trading frequencies. The Ichimoku trading-agent consists of 6 elements (as in Ichimoku trading system [17]).

Tenkan-sen calculation: (highest high + lowest low) $/ 2$ for the last 9 periods. It is primarily used as a signal line and a minor support/resistance line. The Tenkan Sen is an indicator of the market trend. If the red line is moving up or down, it indicates that the market is trending. If it moves horizontally, it signals that the market is ranging. The Tenkan-sen Line is computed below.

$$
T S=\frac{\max \left(s_{9}\right)-\min \left(s_{9}\right)}{2}
$$

$\mathrm{s}_{9}$ - time series created from last 9 periods.
Kijun-sen calculation: (highest high + lowest low) $/ 2$ for the past 26 periods. This is a confirmation line, a support/resistance line, and can also be used as a trailing stop line. The Kijun Sen acts as an indicator of future price movement. If the price is higher than the blue line, it could continue to climb higher. If the price is below the blue line, it could keep dropping. The Kijun-sen Line is computed below.

$$
K S=\frac{\max \left(s_{26}\right)+\min \left(s_{26}\right)}{2}
$$

$\mathrm{S}_{26}$ - time series created from last 26 periods.

Senkou span A calculation: (Tenkan-sen + kijun-sen)/2 plotted 26 periods ahead. Also called leading span 1, this line forms one edge of the kumo, or cloud if the price is above the Senkou span, the top line serves as the first support level while the bottom line serves as the second support level. If the price is below the Senkou span, the bottom line forms the first resistance level while the top line is the second resistance level. Span is computed below.

$$
S S A=\frac{T S+K S}{2}
$$

TS - tenkan-sen line,

KS - tenkan-sen line.

Senkou span B calculation: (highest high + lowest low)/2 calculated over the past 52 time periods and plotted 26

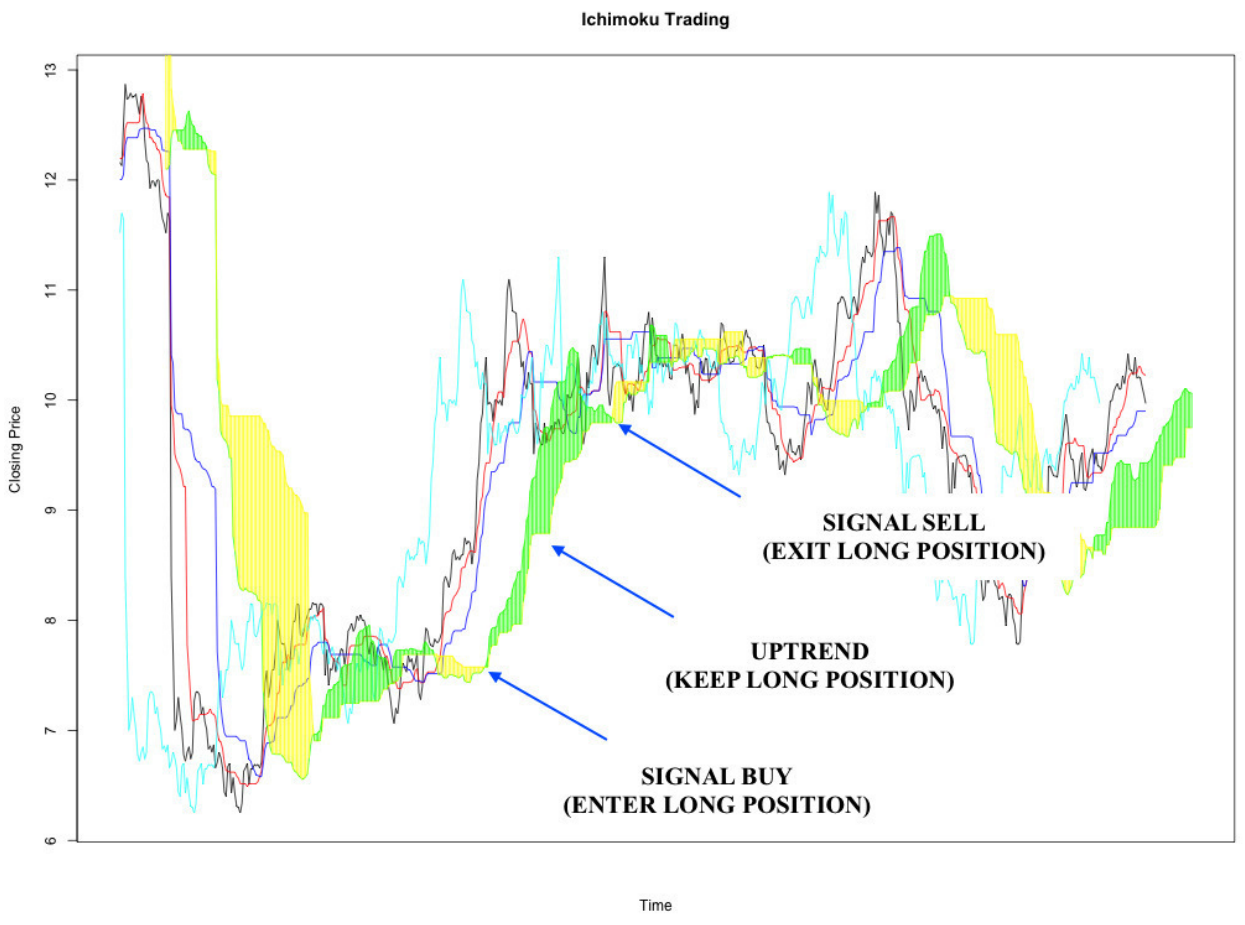

Fig. 1 Ichimoku Trading - entering and exiting long positions (symbol ORANGEPL). 
periods ahead. Also called leading span 2, this line forms the other edge of the kumo. Span is computed below.

$$
S S B=\frac{\max \left(s_{52}\right)+\min \left(s_{52}\right)}{2}
$$

$\mathrm{S}_{52}$ - time series created from last 26 periods.

Kumo cloud is the space between senkou span A and B. The cloud edges identify current and potential future support and resistance points. The Kumo cloud changes in shape and height based on price changes. The Kumo height represents volatility as larger price movements form thicker clouds, which creates a stronger support and resistance. As thinner clouds offer only weak support and resistance, prices can and tend to break through. Generally, markets are bullish when Senkou Span A is above Senkou Span B and vice versa. Traders often look for Kumo Twists in future clouds, where Senkou Span A and B exchange positions, a signal of potential trend reversals. In addition to thickness, the strength of the cloud can also be ascertained by its angle; upwards for bullish and downwards for bearish. Any clouds behind price are also known as Kumo Shadows.

Chikou line calculation: today's closing price projected back 26 days on the chart. Also called the lagging span it is used as a support/resistance aid. If the Chikou Span or the green line crosses the price in the bottom-up direction, that is a buy signal. If the green line crosses the price from the top-down, that is a sell signal. Visually the rules implemented in automated-strategy are presented on the figure 1.

Figure 1 shows all Ichimoku elements with entry and exit positions. The colors on the figure corresponds to listed below Ichimoku elements:

- red Tenka-sen line,

- blue Kijun-sen line,

- green Senkou span A,

- yellow Senkou span B,

- cyan Chikou line.

It is important to avoid biases related to backtesting buyonly strategies on uptrend markets only. Therefore the backtests were conducted during diversified market periods. Fig. 2 shows corresponding WIG30 period (daily observations).

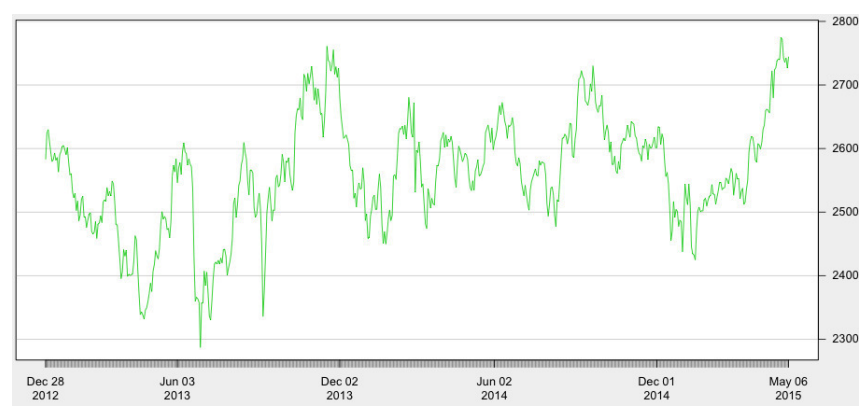

Fig. 2 WIG30, in backtested period, presenting non-monotonous trend.

During the backtested period the daily WIG30 returns had moderate skewness, with mean centered almost around zero. The weekly and monthly WIG30 returns were also slightly positive, with no significant variance. The summary of basic statistics is presented in table 1 .

The backtests were performed in A-Trader with extensions written in $\mathrm{R}$ programming language. The reason of choosing $\mathrm{R}$ is because it is well tested statistical programming framework with wide variety of libraries and large community. This approach makes the backtests less vulnerable to errors. The backtesting architecture, presented in detail in [16], is shown at the fig. 3.

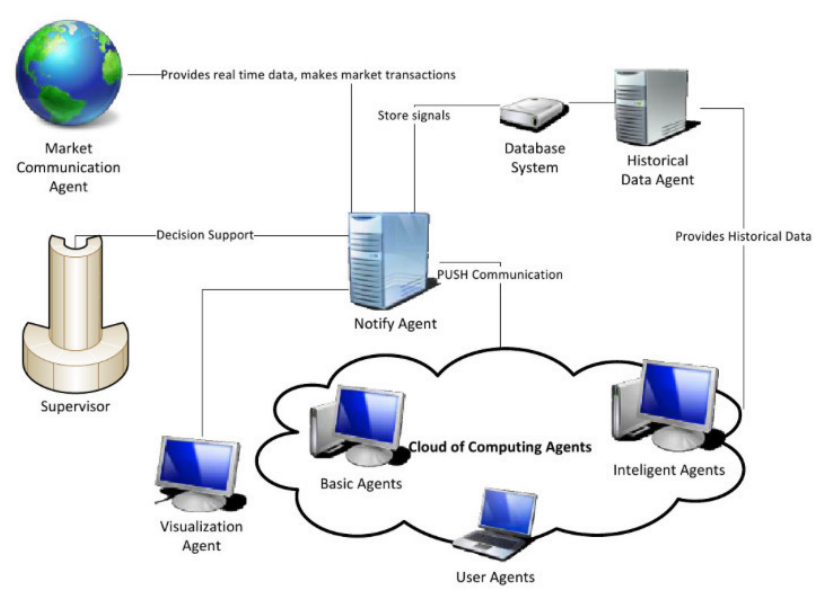

Fig. 3 A-Trader architecture.

TABLE I.

STATISTICS OF WIG30 RETURNS - VARIOUS TIME RESOLUTIONS

\begin{tabular}{|l|r|r|r|r|r|r|r|r|}
\hline Returns & \multicolumn{1}{|l|}{ \# Obs } & \multicolumn{1}{l|}{ Minimum } & \multicolumn{1}{l|}{ Quartile 1 } & \multicolumn{1}{l|}{ Median } & \multicolumn{1}{l|}{ Mean } & \multicolumn{1}{l|}{ Quartile 3 } & \multicolumn{1}{l|}{ Maximum } & \multicolumn{1}{l|}{ Stdev } \\
\hline Daily & 581 & -0.0527 & -0.0054 & 0.0030 & 0.002 & 0.0057 & 0.0311 & 0.0097 \\
\hline Weekly & 123 & -0.0865 & -0.0122 & 0.0019 & 0.007 & 0.0126 & 0.0578 & 0.0217 \\
\hline Monthly & 29 & -0.0877 & -0.0189 & 0.0031 & 0.0028 & 0.0328 & 0.0818 & 0.0386 \\
\hline
\end{tabular}


The following agents and components are distinguished in the A-Trader architecture:

- Notify Agent (NA),

- Historical Data Agent (HDA),

- Cloud of Computing Agents (CCA),

- Market Communication Agent (MCA),

- User Communication Agent (UCA),

- Supervisor (S),

- Database System (DS).

The data was acquired from the brokerage department of BOS Bank (the Polish Bank Ochrony Środowiska). Data was aggregated to 1-day periods. As a middle storage layer, a HDFS distributed file system was used. Such approach enables huge improvements in computation time and allows the data to perform millions of simulation in real time. These extensions of the A-Trader built framework are easily customizable and can be used in a variety of tests with minimum programming work.

\section{RESULTS}

For the purpose of backtesting we took components of WIG 30 index (as of 2015.05.07). The list of backtested companies included: ALIOR, ASSECOPOL, BOGDANKA, BORYSZEW, BZWBK, CCC, CYFRPLSAT, ENEA, ENERGA, EUROCASH, GRUPAAZOTY, GTC, HANDLOWY, INGBSK, JSW, KERNEL, KGHM, LOTOS, LPP, MBANK, ORANGEPL, PEKAO, PGE, PGNIG, PKNORLEN, PKOBP, PZU, SYNTHOS, TAURONPE, TVN. Next, the data was trimmed to the earliest possible point where the WIG30 index provides first observation (2012-12-28). Additionally the company quotes were shifted by 52 trading days to prepare signals for trading since the first day of WIG30 (2012-10-12).

Each of the benchmarks produced a visual output of Ichimoku components with price. Additionally, cumulative returns of the tested trend-following strategy were plotted along the classical "Buy \& Hold" benchmark.

Visual examination of two different results of strategies helps understand the mechanics of gains and losses. The first example shows a situation where the cumulative return of trend following-strategy outperformed the Buy \& Hold benchmark. Figure 4 presents the company with symbol GRUPAAZOTY and its Ichimoku components. Figure 5 presents cumulative returns.

Opposite to the previous example where Buy \& Hold outperformed, the trend following Ichimoku strategy is presented on figures 6 (flags, lines) and 7 (cumulative returns).

Final summary of the results leave no doubts. The trend following strategy performed worse than Buy \& Hold in 26 out of 30 cases. In most cases, the winning situations were merely protecting losing positions. The table 2 presents

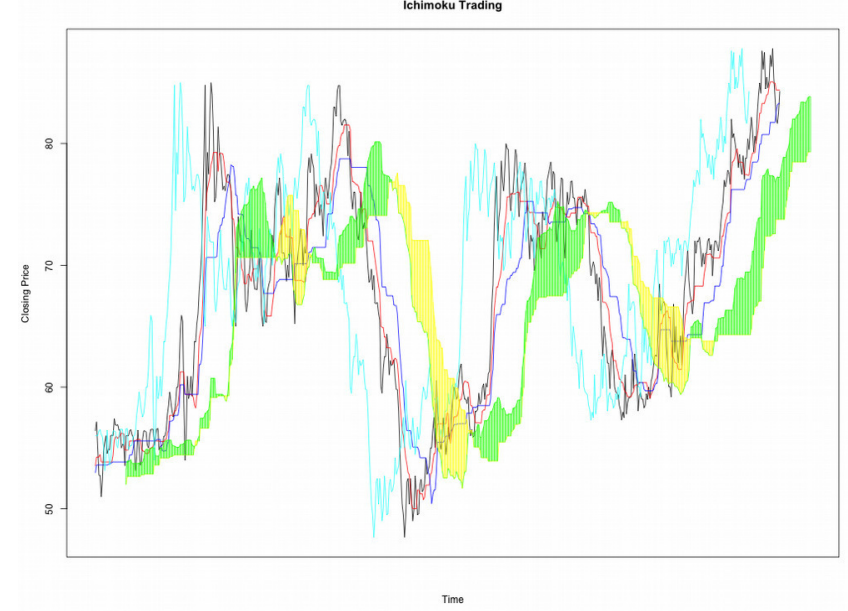

Fig. 4 Ichimoku flags and lines for GRUPAAZOTY.

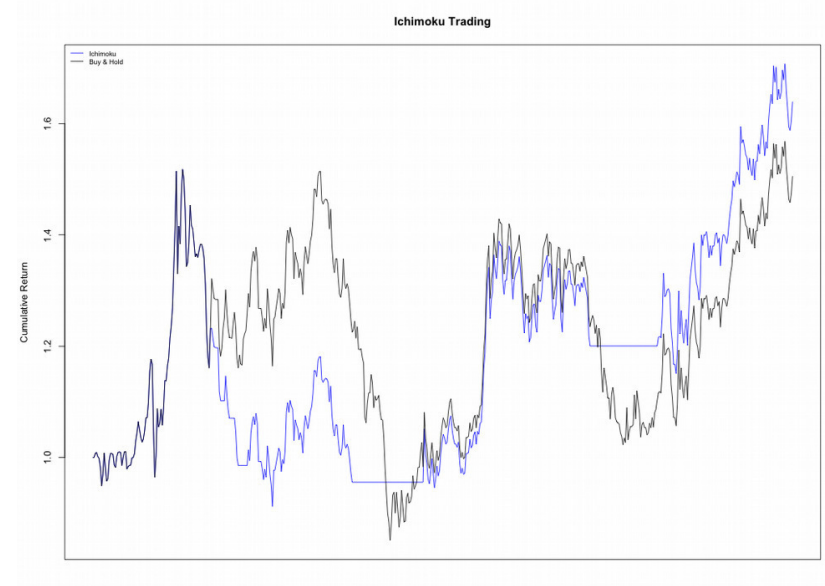

Fig. 5 Cumulative returns - comparison of Ichimoku and Buy \& Hold strategies (GRUPAAZOTY).

summary of the results for all the companies in the backtests. The numbers in column I and II show cumulative returns. Values below "1" are losses of initial capital.

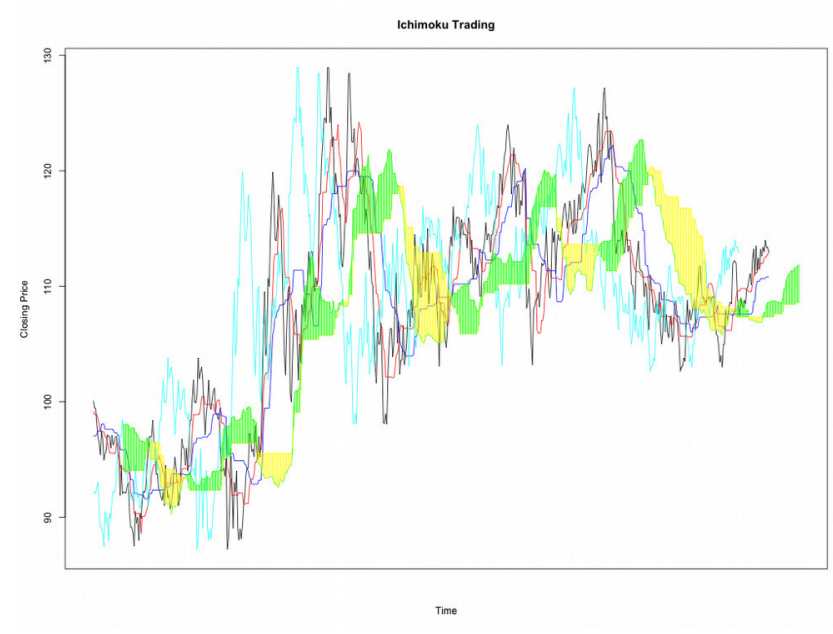

Fig. 6 Ichimoku flags and lines for HANDLOWY. 


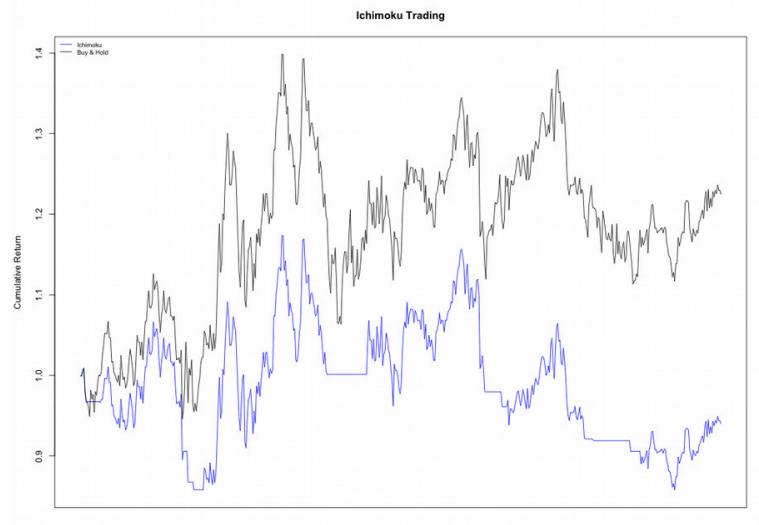

Fig. 7 Cumulative returns - comparison of Ichimoku and Buy \& Hold strategies (HANDLOWY).

The statistics of cumulative returns across backtests is presented in table III.

\section{DISCUSSION}

As shown in backtests buying winners on Warsaw Stock Exchange with Ichimoku short trend following strategy did not perform well. There might be a few reasons for such results.

First is past-winners do not have enough strength to beat the market in the future. Buy and hold benchmark seems to confirm this thesis. This is not a typical situation on welldeveloped capital markets where buying winners usually outperform the market [18]. The assets for the backtests were taken from the WIG30 index component list. Perhaps those assets were considered overpriced, due to the short term overreaction to the news, and therefore there was no steady potential to outperform the market. Investigation into other segments of the market might be helpful to verify this statement.

Second reason of the losses is the potential inefficiency of Ichimoku technique as the trend following strategy. There is a possibility that Ichimoku with used parameters does not follow trend as intended. In such cases, further backtests with different strategies might deny or confirm this thesis. However looking at the Buy \& Hold strategy, it seems that the buying "winners" approach is the problem, not the chosen strategy itself. Nevertheless other strategies might shed some additional light on this matter.

In general, trend following scored worse in almost every case, except one: investment protection. The minimum Buy \& Hold cumulative return is 0.1562 , while, for trend following, the protection shut the trading down at 0.4646 . Although this additional protection limits losses, it also trims gains.

Final conclusions are that joining recently established uptrends, in the case of WIG30 components in period 201212-28 to 2015-05-06, did not lead to excessive returns and did not provide any other kind of improvements. Of course, the presented backtesting approach is very general: the
TABLE II.

STATISTICS OF WIG30 RETURNS - VARIOUS TIME RESOLUTIONS

\begin{tabular}{|c|c|c|c|}
\hline $\begin{array}{c}\text { Trend } \\
\text { Following }\end{array}$ & Buy \& Hold & Symbol & Result \\
\hline 0,95 & 1,32 & ALIOR & LOSS \\
\hline 1,38 & 1,39 & ASSECOPOL & LOSS \\
\hline 0,60 & 0,65 & BOGDANKA & LOSS \\
\hline 1,16 & 1,21 & BORYSZEW & LOSS \\
\hline 1,05 & 1,39 & BZWBK & LOSS \\
\hline 2,15 & 2,72 & $\mathrm{CCC}$ & LOSS \\
\hline 1,34 & 1,56 & CYFRPLSAT & LOSS \\
\hline 0,69 & 1,09 & ENEA & LOSS \\
\hline 1,18 & 1,31 & ENERGA & LOSS \\
\hline 0,68 & 0,78 & EUROCASH & LOSS \\
\hline 1,64 & 1,51 & GRUPAAZOTY & WIN \\
\hline 0,89 & 0,74 & GTC & WIN \\
\hline 0,94 & 1,22 & HANDLOWY & LOSS \\
\hline 1,52 & 1,62 & INGBSK & LOSS \\
\hline 0,61 & 0,16 & JSW & WIN \\
\hline 0,46 & 0,54 & KERNEL & LOSS \\
\hline 0,59 & 0,69 & KGHM & LOSS \\
\hline 0,73 & 0,84 & LOTOS & LOSS \\
\hline 1,32 & 1,42 & LPP & LOSS \\
\hline 1,19 & 1,48 & MBANK & LOSS \\
\hline 1,16 & 0,87 & ORANGEPL & WIN \\
\hline 0,78 & 1,21 & PEKAO & LOSS \\
\hline 1,00 & 1,22 & PGE & LOSS \\
\hline 1,13 & 1,20 & PGNIG & LOSS \\
\hline 1,00 & 1,38 & PKNORLEN & LOSS \\
\hline 0,84 & 1,06 & РКОВР & LOSS \\
\hline 0,80 & 1,18 & PZU & LOSS \\
\hline 0,75 & 0,94 & SYNTHOS & LOSS \\
\hline 0,85 & 1,11 & TAURONPE & LOSS \\
\hline 1,86 & 1,89 & TVN & LOSS \\
\hline
\end{tabular}

algorithms can be adjusted, additional variables can be specified, and more sophisticated models can be used. However, the broad backtests performed in this research 
TABLE III.

STATISTICS BETWEEN RETURNS ACROSS ASSETS

\begin{tabular}{|c|c|c|}
\hline & $\begin{array}{l}\text { Trend Following } \\
\text { (Ichimoku) }\end{array}$ & Buy \& Hold \\
\hline Min. & 0.4646 & 0.1562 \\
\hline 1st qu & 0.7579 & 0.8830 \\
\hline Median & 0.9768 & 1.2070 \\
\hline Mean & 1.0424 & 1.1884 \\
\hline 3rd qu & 1.1890 & 1.3911 \\
\hline Max. & 2.1539 & 2.7209 \\
\hline
\end{tabular}

negate momentum, and suggest contrarian nature of WIG30 components.

\section{REFERENCES}

[1] Lempérière, Y., Deremble, C., Seager, P., Potters, M., \& Bouchaud, J. P. (2014). Two centuries of trend following. arXiv preprint arXiv: 1404.3274 .

[2] Sasaki, Hidendobu, "Ichimoku Kinko Studies", Toshi Raider Publishing, 1996

[3] Burghardt, G. \& Walls, B. (2011). Two benchmarks for momentum trading. Managed Futures for Institutional Investors: Analysis and Portfolio Construction, 99-127. B. Smith, "An approach to graphs of linear forms (Unpublished work style)," unpublished.
[4] Moskowitz, T. J., Ooi, Y. H., \& Pedersen, L. H. (2012). Time series momentum. Journal of Financial Economics, 104(2), 228-250.

[5] Rouwenhorst, K.G., (1998). International momentum strategies, Journal of Finance 53, 267-284.

[6] Rouwenhorst, K.G., (1999) Local return factors and turnover in emerging stock markets, Journal of Finance 54, 1439-1464.

[7] Hameed, A. and K. Yuanto, 2002, Momentum strategies: evidence from the pacific basin stock markets, Journal of Financial Research, 25(3), 383-397.

[8] Schiereck, D., W. DeBondt and M. Weber, 1999, Contrarian and momentum strategies in Germany, Financial Analysts Journal 155,104116 .

[9] Jegadeesh, N., 1990, Evidence of predictable behavior of security returns, Journal of Finance 45 881-898.

[10] Lehmann, B.N., 1990, Fads, martingales and market efficiency, Quarterly Journal of Economics 105, 1-28.

[11] DeBondt, W.F.M. and R. Thaler, 1985, Does the stock market overreact? Journal of Finance 40, 793-805.

[12] DeBondt, W.F.M. and R. Thaler, 1987, Further evidence on investor overreaction and stock market seasonality, Journal of Finance, 42, 557-581.

[13] Chang, R.P., D.W. McLeavey and S.G. Rhee, 1995, Short-term abnormal returns of the contrarian strategy in the Japanese stock market, Journal of Business Finance and Accounting 22, 1035-1048.

[14] Hameed, A. and S. Ting, 2000, Trading volume and short-horizon contrarian profits, evidence from Malaysian stock market, PacificBasin Finance Journal 8, 67-84.

[15] Kang, J., Liu, M. H., and Ni, S. X. (2002) Contrarian and momentum strategies in China stock market: 1993-2000. Pacific-Basin Finance Journal, 10(3): 243-265.

[16] Korczak, Jerzy, et al. "A-Trader-Consulting agent platform for stock exchange gamblers." Computer Science and Information Systems (FedCSIS), 2012 Federated Conference on. IEEE, 2012.

[17] Ichimoku, Sanjin "Ichimoku Kinko Charts", Keizai Hendo Kenkyujo, 1981.

[18] Jegadeesh, at al, "Returns to Buying Winners and Selling Losers: Implications for Stock Market Efficiency", The Journal of Finance, vol. XLVIII, 1993. 